\title{
Efeito de sulfentrazone no sistema integrado palha de cana-de-açúcar, herbicida e vinhaça no desenvolvimento inicial da tiririca (Cyperus rotundus)
}

\author{
Effect of sulfentrazone in the integrated system using sugarcane mulch residue, \\ herbicide and vinasse on purple nutsedge (Cyperus rotundus) initial development
}

\author{
Maria do Carmo de Salvo Soares Novo* ${ }^{1}$, Ricardo Victoria Filho ${ }^{2}$, Fábio Molchanski Langbeck ${ }^{3}$, \\ Antonio Augusto do Lago ${ }^{2}$; Robert Deuber ${ }^{2}$ e Glauco de Souza Rolim ${ }^{2}$
}

Resumo - O objetivo do trabalho foi avaliar o efeito da interação palha de cana-de-açúcar, do herbicida sulfentrazone e de diferentes meios de aplicação de vinhaça no desenvolvimento inicial da tiririca (C. rotundus). O experimento foi instalado em vasos com terra, em casa de vegetação, e disposto em blocos ao acaso, com quatro repetições, sendo avaliados, vinte oito dias após a instalação do experimento, os tratamentos: controle $(\mathrm{C})$; apenas palha $(\mathrm{P})$; apenas vinhaça $(\mathrm{V})$; apenas o herbicida $(\mathrm{H})$, palha + vinhaça $(\mathrm{PV})$; palha + herbicida $(\mathrm{PH})$; herbicida + vinhaça aplicada antes do herbicida (HVa); herbicida + vinhaça aplicada depois do herbicida (HVd); herbicida + vinhaça aplicada junto com o herbicida $(\mathrm{HVj})$; palha + herbicida + vinhaça aplicada antes do herbicida (PHVa); palha + herbicida + vinhaça aplicada depois do herbicida (PHVd); e palha + herbicida + vinhaça aplicada junto com o herbicida $(\mathrm{PHVj})$. Sulfentrazone foi aplicado na dose de $700 \mathrm{~g} \mathrm{ha}^{-1}$ e nos tratamentos $\mathrm{HVj}$ foi diluído com água até $1 / 4$ do volume necessário e completado com vinhaça. $\mathrm{Na}$ análise estatística empregou-se o teste $\mathrm{F}$ e quando houve significância das variáveis, o teste de Scheffé foi usado para avaliar os contrastes: $\mathrm{C} \times \mathrm{H} ; \mathrm{C} \times \mathrm{P}$; $\mathrm{C}$ x V; $\mathrm{C}$ x H; C x tratamentos com palha; $\mathrm{C}$ x tratamentos com vinhaça; sem $\mathrm{H}$ x com $\mathrm{H}$; sem $\mathrm{P}$ x com P; sem V x com V; HVa x HVd; HVa x HVj; HVd x HVj; HVa x PHVa; HVd x PHVd; HVj x PHVj; PHVa x PHVd; PHVa x PHVj e PHVd x PHVj. Para avaliar o nível de umidade da palha foi empregado o teste de Duncan a $5 \%$ de probabilidade. Concluiu-se que sulfentrazone, tanto em aplicação isolada como sobre palha ou associado à vinhaça aplicada antes, depois ou em mistura com o produto, controlou o desenvolvimento inicial da tiririca. A deposição da palha sobre o solo reduziu o desenvolvimento inicial da tiririca, mas aumentou a altura das plantas devido ao estiolamento. A vinhaça aplicada sobre o solo descoberto e sem herbicida estimulou o desenvolvimento da tiririca; entretanto, associada à palha e ao sulfentrazone, reduziu o crescimento. Não houve diferença entre aplicação de vinhaça antes, depois e mesmo em mistura com sulfentrazone nos tratamentos sem ou com palha.

Palavras-chave: cana crua, resíduo da agroindústria, Cyperaceae.

\begin{abstract}
The objective of this work was to evaluate the interactions among sugarcane mulch residue, the herbicide sulfentrazone and different application methods of vinasse, a sugarcane industry residue, on the initial development of purple nutsedge (Cyperus rotundus L.). A greenhouse experiment was set up using pots with soil, in randomized complete blocks, with four replications and the following treatments were studied: control $(\mathrm{C})$, straw alone $(\mathrm{P})$, vinasse alone

\footnotetext{
${ }^{1}$ Pesquisadores Científicos do Instituto Agronômico, Caixa Postal 28, CEP 13020-920 Campinas, SP. E-mail: jpsnovo@iac.sp.gov.br;

${ }^{2}$ Professor Titular, Escola Superior de Agricultura Luiz de Queiróz, USP, Piracicaba, SP;

${ }^{3}$ Acadêmico do curso de Ciências Biológicas da Pontifícia Universidade Católica de Campinas, Campinas, SP.
}

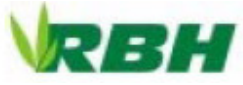


$(\mathrm{V})$, herbicide alone $(\mathrm{H})$, straw + vinasse $(\mathrm{PV})$, straw + herbicide $(\mathrm{PH})$, herbicide + vinasse applied before the herbicide ( $\mathrm{HVa})$, herbicide + vinasse applied after the herbicide (HVd), herbicide + vinasse applied together $(\mathrm{HVj})$, straw + herbicide + vinasse applied before the herbicide (PHVa), straw + herbicide + vinasse applied after the herbicide (PHVd) and straw + herbicide + vinasse applied together $(\mathrm{PHVj})$. Sulfentrazone was applied at the rate of $700 \mathrm{~g} \mathrm{ha}^{-1}$, and in the treatments $\mathrm{HVj}$, sulfentrazone was diluted in water until $1 / 4$ of the necessary volume, the remaining $3 / 4$ being completed with vinasse. In the statistical analysis the $\mathrm{F}$ test was used while the Scheffé test was employed to study the following contrasts: $\mathrm{C} \times \mathrm{H}, \mathrm{C} \times \mathrm{P}, \mathrm{Cx} \mathrm{V}, \mathrm{C} \times$ treatments with $\mathrm{H}, \mathrm{C} \times$ treatments with $\mathrm{S} ; \mathrm{C} \times$ treatments with $\mathrm{V}$; without herbicide $\mathrm{x}$ with herbicide; without straw $\mathrm{x}$ with straw, without vinasse $\mathrm{x}$ with vinasse, $\mathrm{HVa} \times \mathrm{HVd} ; \mathrm{HVa} \times \mathrm{HVj}$, HVa x HVj; HVa x SHVa, HVd x SHVd, HVj x SHVj, SHVa x SHVd, SHVd x SHVj and SHVd $\mathrm{x}$ SHVj. It was uses the Duncan's test for the umidity straw avaliation. It was concluded that sulfentrazone applied alone or on the sugar cane mulch residue or with vinasse applied before, after or in mixture with herbicide controlled the initial development of purple nutsedge. Sugar cane mulch residue reduced the initial development of purple nutsedge but the height of plants was increased due to etiolation. Vinasse applied on the soil without sugar cane mulch residue and without sulfentrazone stimulated the development of this weed. There wasn't difference among appling vinasse before, after or in mixture with sulfentrazone in the treatments with or without straw.

Key-words: sugarcane mulch residue, agroindustry residue, Cyperaceae.

\section{Introdução}

No Brasil, em muitas áreas cultivadas com cana-de-açúcar ainda adota-se a queimada na colheita com a finalidade de eliminar grande parte dos restos de vegetais e alguns animais peçonhentos, facilitando o trabalho dos cortadores e o transporte dos toletes para a usina (Azania et al., 2006).

Por motivo legal, no Estado de São Paulo, o emprego do fogo está sendo substituído gradualmente por colheita mecanizada sendo que, na safra de 1999/2000, em aproximadamente, $25 \%$ da área produtora de cana do Brasil esta técnica já estava sendo adotada. Na colheita mecanizada, as folhas verdes, as secas e os ponteiros são picados e permanecem sobre a superfície do solo formando uma camada de palha que pode alcançar de 0,08 a 0,10 $\mathrm{m}$ de espessura. De acordo com Trivellin et al. (1996), a quantidade de palha deixada sobre o solo sob condição de cana crua, dependendo da cultivar e do tipo de solo, varia de 10 a $30 \mathrm{t} \mathrm{ha}^{-1}$ podendo proporcionar estímulo à germinação e ao desenvolvimento de algumas espécies e redução de outras (Martins et al., 1999).

Com a adoção do sistema de colheita mecanizada e sem queima da palhada ocorrem modificações das condições químicas, físicas e biológicas do solo. Além de influenciar a incidência de plantas daninhas, a adição de palhada aumenta a atividade microbiana, o teor de matéria orgânica e favorece a adsorção dos herbicidas no solo (Medeiros, 2001). Segundo Ferri \& Vidal (2002), em área sob palhada, a manutenção da estabilidade da estrutura, com a possibilidade de ocorrência de fluxo preferencial, em razão do aumento de macroporos, pode ser considerada um mecanismo de aumento da lixiviação.

A composição florística da planta daninha da área sob cana crua também 
apresenta mudanças tendo em algumas espécies aumentada sua importância (Kuva, 2006), porém não afeta a tiririca. A tiririca é uma planta de ciclo fotossintético $\mathrm{C}_{4}$ que devido a sua agressividade e rusticidade é difícil de ser controlada (Azania et al., 2006). É uma das principais infestantes dos canaviais sendo mais prejudicial no estádio inicial de desenvolvimento da cultura.

A tiririca tem se tornado um problema mais sério devido ao uso de herbicidas que controlam a maioria das plantas anuais, mas são ineficazes contra ela, à diminuição do uso de cultivadores, de capinas e de arações profundas que poderiam expor os tubérculos ao sol; ao uso intensivo do solo para obter produtividades mais elevadas (Zandstra \& Nishimoto, 1977). Uma das maneiras de manejar a tiririca é com herbicidas de préemergência que para serem eficientes devem atingir a superfície do solo. Entretanto, quando aplicados sobre a palhada, parte pode ser interceptado sendo, em alguns casos, retidos em maior ou em menor quantidade.

Com a colheita da cana crua, a cobertura no solo pode diminuir a quantidade de herbicidas aplicados por fornecer um meio não químico de redução do impacto da interferência por plantas daninhas. Segundo Teasdale (1996), o emprego de cobertura do solo para controlar plantas daninhas tem como objetivo principal a substituição de uma população não manejável por uma cobertura que pode ser manejada. Com isso ocorre um ajustamento da fenologia da cultura para preencher o espaço antes ocupado por populações de espécies infestantes.

A vinhaça é o principal efluente líquido obtido da destilação do álcool e por possuir demanda química de oxigênio muito alta, que aliado ao seu baixo $\mathrm{pH}$, constitui uma fonte de contaminação de águas superficiais, de lençóis de água e do ambiente (Voll, 2005). Para evitar problemas ambientais, a aplicação da vinhaça na cultura da cana-de-açúcar foi adotada pela maioria das usinas produtoras de álcool e açúcar, podendo ser aplicada por meio de caminhões-tanques, sulcos de infiltração e aspersão, existindo ainda a possibilidade da aplicação do resíduo diluído através de pivôs centrais. Sua aplicação deve ser feita, preferencialmente, logo após o corte da canade-açúcar, antes da brotação, pois esse procedimento parece influenciar favoravelmente a brotação das soqueiras (Buss, 1977). Seu teor de nutrientes varia de acordo com o tipo de mosto utilizado na destilaria sendo considerado um fertilizante orgânico e mineral devido aos elevados teores de matéria orgânica e de potássio (Buss, 1977), podendo substituir adubações se aplicado racionalmente.

Com a adição da vinhaça ao solo, ocorre elevação do $\mathrm{pH}$ e do teor de matéria orgânica, aumentando a disponibilidade de alguns nutrientes, o poder de retenção dos cátions, estimulando a atividade microbiana (Quintela et al., 2002). Como a vinhaça é constituída por diversos ácidos orgânicos, além de ser empregada na correção do solo, pode ser utilizada no controle de algumas espécies daninhas alterando a quantidade, o fluxo de emergência e a ação dos herbicidas (Quintela et al., 2002). Christoffoleti \& Bacchi (1985) avaliaram o efeito de doses de vinhaça sobre a incidência de plantas daninhas e constataram que as emergências de Digitaria horizontalis, C. rotundus, Sida rhombifolia e Emilia sonchifolia foram reduzidas.

A presença da palha na superfície do terreno dificulta o transporte do herbicida até o solo e a aplicação da vinhaça na palhada pode ter ação de doadora de prótons e assim levar o produto até o solo (Rodella \& Ferrari, 1997). Em 1976, Buss \& Silva verificaram a viabilidade do uso de herbicidas em mistura com vinhaça para o controle de plantas daninhas na cultura de cana-de-açúcar. Observaram que a eficiência no controle dessas espécies foi significativamente aumentada para alguns herbicidas misturados com vinhaça, 
quando comparados com métodos tradicionais de aplicação destes produtos.

Há escassez de trabalho envolvendo o manejo de plantas daninhas em sistema integrado empregando palha, vinhaça e herbicidas na cultura da cana-de-açúcar. $\mathrm{O}$ objetivo do trabalho foi avaliar o efeito da interação entre palha de cana-de-açúcar, o herbicida sulfentrazone e diferentes meios de aplicação da vinhaça no desenvolvimento inicial da tiririca.

\section{Material e métodos}

Tabela 1. Resultado das análises químicas do solo, da palha e da vinhaça e granulométrica do solo.

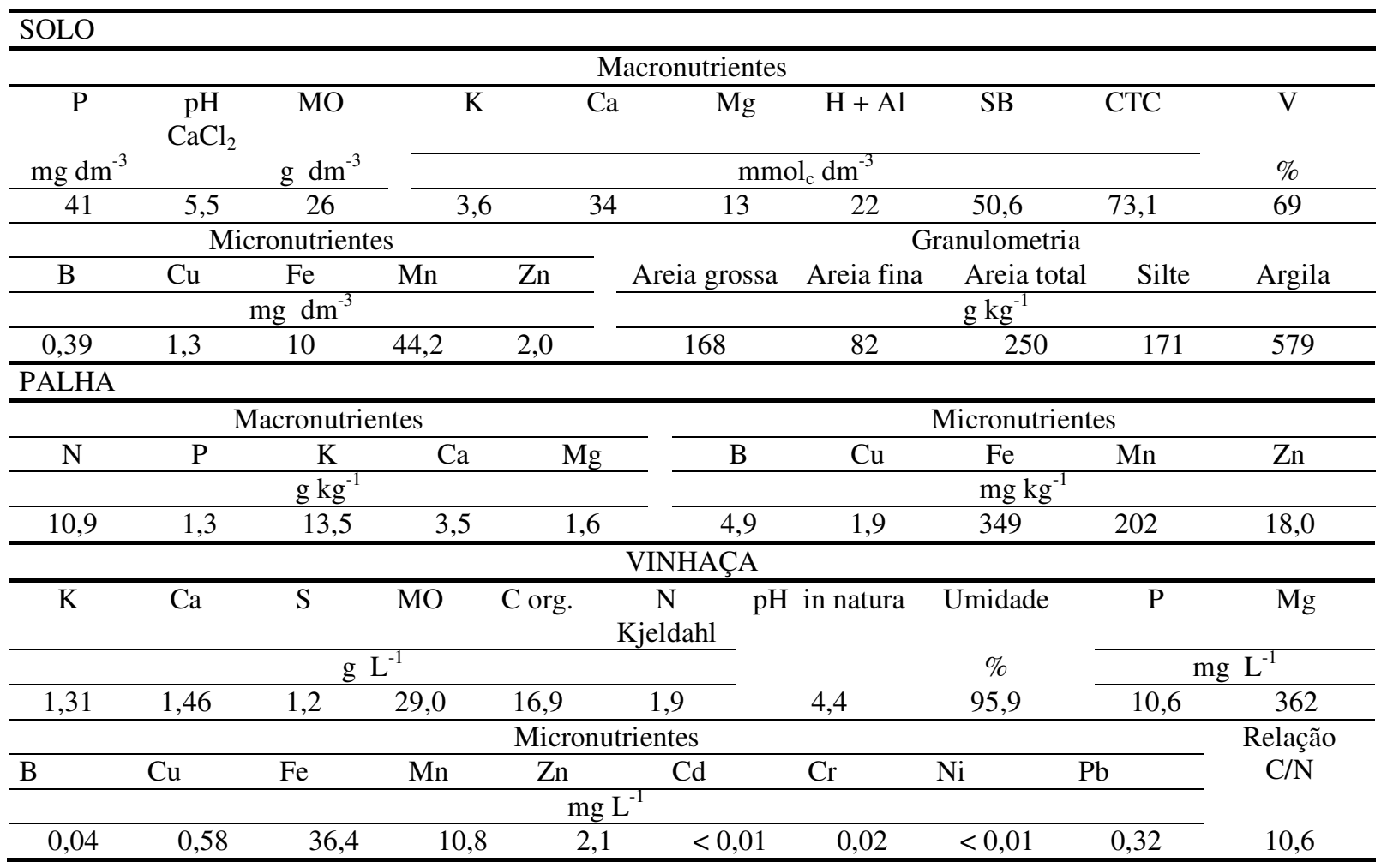

Quatro tubérculos de tiririca com quatro repetições. Os tratamentos avaliados biomassa fresca unitária média de $0,5 \mathrm{~g}$ foram foram: controle $(\mathrm{C})$; apenas palha $(\mathrm{P})$; apenas plantados em cada vaso na profundidade de vinhaça $(\mathrm{V})$; apenas o herbicida $(\mathrm{H})$, palha + $0,03 \mathrm{~m}$. Os vasos foram dispostos em blocos ao vinhaça $(\mathrm{PV})$; palha + herbicida $(\mathrm{PH})$; acaso sendo avaliado doze tratamentos com herbicida + vinhaça aplicada antes do herbicida 
(HVa); herbicida + vinhaça aplicada depois do herbicida (HVd); herbicida + vinhaça aplicada junto com o herbicida $(\mathrm{HVj})$; palha + herbicida + vinhaça aplicada antes do herbicida (PHVa); palha + herbicida + vinhaça aplicada depois do herbicida (PHVd); e palha + herbicida + vinhaça aplicada junto com o herbicida (PHVj).

Após o plantio dos tubérculos, foi colocada sobre o solo palha de cana-de-açúcar, Saccharum spp cv 80-1842, na quantidade correspondente a $15 \mathrm{t} \mathrm{ha}^{-1}$. A palha, cuja análise de fertilidade encontra-se na Tabela 1, foi coletada na Usina Costa Pinto, Charqueada, SP, e por ocasião da instalação do experimento estava com $12,92 \%$ de umidade. A vinhaça proveniente de tanques de armazenamento da mesma usina, cuja análise de fertilidade também é apresentada na Tabela 1, foi aplicada com regador na dose correspondente a $150 \mathrm{~m}^{3}$ $\mathrm{ha}^{-1}$.

Sulfentrazone foi aplicado na dose de $700 \mathrm{~g} \mathrm{ha}^{-1}$ com pulverizador costal pressurizado a $2,1 \mathrm{kgf} \mathrm{cm}^{-2}$, munido de barra com quatro bicos do tipo $80.02 \mathrm{E}$ distanciados entre si em $0,50 \mathrm{~m}$ e a $0,50 \mathrm{~m}$ de altura dos vasos, com gasto de calda correspondente a $400 \mathrm{~L} \mathrm{ha}^{-1}$. Nos tratamentos $\mathrm{HVj}, \quad$ o sulfentrazone foi diluído com água até $1 / 4$ do volume necessário e completado com vinhaça.

Tabela 2. Índices empregados nos diferentes tratamentos para os contrastes: 1) controle versus tratamento com apenas sulfentrazone; 2) controle versus tratamento com apenas palha; 3) controle versus tratamento com apenas vinhaça; 4) controle versus tratamentos com herbicidas; 5) controle versus tratamentos com palha; 6) controle versus tratamentos com vinhaça; 7) sem herbicida versus com herbicida; 8) sem palha versus com palha; 9) sem vinhaça versus com vinhaça; 10) $\mathrm{HVa}$ versus $\mathrm{HVd}$; 11) $\mathrm{HVa}$ versus $\mathrm{HVj}$; 12) $\mathrm{HVd}$ versus $\mathrm{HVj}$; 13) $\mathrm{HVa}$ versus PHVa; 14) HVd versus PHVd; 15) HVj versus PHVj; 16) PHVa versus PHVd; 17) PHVa versus PHVj e 18) PHVd versus PHVj analisados no experimento.

\begin{tabular}{|c|c|c|c|c|c|c|c|c|c|c|c|c|c|c|c|c|c|c|}
\hline \multirow[b]{2}{*}{ Tratam. } & \multicolumn{18}{|c|}{ Número do contraste } \\
\hline & 1 & 2 & 3 & 4 & 5 & 6 & 7 & 8 & 9 & 10 & 11 & 12 & 13 & 14 & 15 & 16 & 17 & 18 \\
\hline $\mathrm{C}$ & 1 & 1 & 1 & 8 & 6 & 8 & 2 & 1 & 2 & 0 & 0 & 0 & 0 & 0 & 0 & 0 & 0 & 0 \\
\hline $\mathrm{H}$ & -1 & 0 & 0 & -1 & 0 & 0 & $1-$ & 1 & 2 & 0 & 0 & 0 & 0 & 0 & 0 & 0 & 0 & 0 \\
\hline $\mathrm{P}$ & 0 & -1 & 0 & 0 & -1 & 0 & 2 & -1 & 2 & 0 & 0 & 0 & 0 & 0 & 0 & 0 & 0 & 0 \\
\hline V & 0 & 0 & -1 & 0 & 0 & -1 & 2 & 1 & -1 & 0 & 0 & 0 & 0 & 0 & 0 & 0 & 0 & 0 \\
\hline $\mathrm{PH}$ & 0 & 0 & 0 & -1 & -1 & 0 & -1 & -1 & 2 & 0 & 0 & 0 & 0 & 0 & 0 & 0 & 0 & 0 \\
\hline PV & 0 & 0 & 0 & 0 & -1 & -1 & 2 & -1 & -1 & 0 & 0 & 0 & 0 & 0 & 0 & 0 & 0 & 0 \\
\hline $\mathrm{HVa}$ & 0 & 0 & 0 & -1 & 0 & -1 & -1 & 1 & -1 & 1 & 1 & 0 & 1 & 0 & 0 & 0 & 0 & 0 \\
\hline HVd & 0 & 0 & 0 & -1 & 0 & -1 & -1 & 1 & -1 & -1 & 0 & 1 & 0 & 1 & 0 & 0 & 0 & 0 \\
\hline $\mathrm{HVj}$ & 0 & 0 & 0 & -1 & 0 & -1 & -1 & 1 & -1 & 0 & -1 & -1 & 0 & 0 & 1 & 0 & 0 & 0 \\
\hline PHVa & 0 & 0 & 0 & -1 & -1 & -1 & -1 & -1 & -1 & 0 & 0 & 0 & -1 & 0 & 0 & 1 & 1 & 0 \\
\hline PHVd & 0 & 0 & 0 & -1 & -1 & -1 & -1 & -1 & -1 & 0 & 0 & 0 & 0 & -1 & 0 & -1 & 0 & 1 \\
\hline $\mathrm{PHVj}$ & 0 & 0 & 0 & -1 & -1 & -1 & -1 & -1 & -1 & 0 & 0 & 0 & 0 & 0 & -1 & 0 & -1 & -1 \\
\hline
\end{tabular}

Vinte e oito dias após a pulverização, retirou-se a palha dos vasos, contou-se o número de brotações e mediu-se a altura das plantas de tiririca. Avaliou-se o número de tubérculos e as biomassas frescas e secas de raiz, parte aérea e de tubérculos. As biomassas secas foram determinadas após secagem do material fresco em estufa a $65^{\circ} \mathrm{C}$ até peso constante. Também foram determinados os teores de umidade do solo e da palha. 
$\mathrm{O}$ efeito dos tratamentos foi analisado estatisticamente empregando-se o teste F. Para a análise estatística, os dados de número de tubérculos e de brotações foram transformados em $\sqrt{x+1}$ e os de porcentagem de umidade do solo e da palha em arc sen $\sqrt{x / 100}$.

As médias, quando significativas, foram comparadas pelo teste de Scheffé. Foi escolhido o teste de Scheffé, pois esse não exige que os contrastes sejam ortogonais e não há número máximo de contrastes a serem analisados (Pimentel Gomes, 1976).

Foram avaliados os seguintes contrastes: $\mathrm{C} \times \mathrm{H}, \mathrm{C} \times \mathrm{P}, \mathrm{C} \times \mathrm{V}$, controle $\mathrm{x}$ tratamentos com herbicidas $(\mathrm{C} \times \mathrm{CH})$; controle $\mathrm{x}$ tratamentos com palha $(\mathrm{C} \times \mathrm{CP})$; controle $\mathrm{x}$ tratamentos com vinhaça $(\mathrm{C} \times \mathrm{CV})$; sem herbicida x com herbicida ( $\mathrm{SH} \times \mathrm{CH}$ ); sem palha $\mathrm{x}$ com palha (SP x CP); sem vinhaça $\mathrm{x}$ com vinhaça (SV x CV); HVa x HVd; HVa x $\mathrm{HVj}$; HVd x HVj; HVa x PHVa; HVd x PHVd; $\mathrm{HVj}$ versus $\mathrm{PHVj}$; PHVa $\mathrm{x}$ PHVd; PHVa $\mathrm{x}$ PHVj e PHVd $x$ PHVj. Os índices empregados nos diferentes contrastes são apresentados na Tabela 2. As médias do teor de umidade de palha foram comparadas pelo teste de Duncan a $5 \%$.

\section{Resultados e discussão}

Os valores médios das diferentes variáveis analisadas são apresentados na Tabela 3. Observou-se que os maiores valores foram observados no tratamento com apenas vinhaça (V) e os tratamentos com palha favoreceram o aumento da água no solo.

Tabela 3. Valores médios das variáveis: número de tubérculos $(\mathrm{NT})$, número de brotações $(\mathrm{NB})$, biomassas frescas de raiz (BFR), da parte aérea (BFPA) e de tubérculos (BFT), altura média de plantas, biomassas secas de raiz (BSR), da parte aérea (BSPA) e de tubérculos (BST) e porcentagem de Umidade do Solo (USolo) por tratamento. Médias de quatro repetições. Campinas, SP, 2003.

\begin{tabular}{|c|c|c|c|c|c|c|c|c|c|c|}
\hline \multirow[t]{2}{*}{ Trat. } & $\mathrm{NT}^{1}$ & $\mathrm{NB}^{1}$ & BFR & BFPA & BFT & \multirow{2}{*}{$\begin{array}{c}\text { Altura } \\
\mathrm{cm}\end{array}$} & BSR & BSPA & BST & \multirow{2}{*}{$\begin{array}{c}\mathrm{U} \mathrm{Solo}^{2} \\
\%\end{array}$} \\
\hline & & & & g vaso $^{-1}$ & & & & g vaso $^{-1}$ & & \\
\hline $\mathrm{C}$ & 9,62 & 9,21 & 12,36 & 9,99 & 6,80 & 20,28 & 1,20 & 1,70 & 1,07 & 20,41 \\
\hline $\mathrm{H}$ & 4,00 & 0,00 & 3,65 & 0,00 & 2,53 & 0,00 & 0,18 & 0,00 & 0,44 & 25,35 \\
\hline $\mathrm{P}$ & 5,63 & 5,49 & 8,94 & 3,21 & 1,94 & 14,54 & 0,78 & 0,67 & 0,56 & 33,88 \\
\hline V & 16,30 & 18,10 & 35,52 & 30,88 & 6,75 & 20,56 & 4,52 & 3,86 & 1,29 & 22,21 \\
\hline $\mathrm{PH}$ & 5,94 & 13,62 & 15,00 & 30,45 & 2,53 & 18,66 & 0,94 & 3,77 & 0,46 & 23,53 \\
\hline PV & 4,0 & 4,49 & 6,60 & 2,10 & 2,30 & 14,24 & 0,63 & 0,43 & 0,40 & 30,80 \\
\hline $\mathrm{HVa}$ & 4,0 & 0,00 & 2,72 & 0,00 & 2,56 & 0,00 & 0,18 & 0,00 & 0,43 & 28,75 \\
\hline $\mathrm{HVd}$ & 3,24 & 0,00 & 0,89 & 0,00 & 2,17 & 0,00 & 0,24 & 0,00 & 0,37 & 29,62 \\
\hline $\mathrm{HVj}$ & 4,0 & 0,00 & 4,00 & 0,00 & 2,35 & 0,00 & 0,16 & 0,00 & 0,41 & 25,89 \\
\hline PHVa & 4,0 & 0,00 & 6,89 & 0,00 & 2,06 & 0,00 & 0,61 & 0,00 & 0,36 & 34,29 \\
\hline PHVd & 3,74 & 0,00 & 4,27 & 0,00 & 2,72 & 0,00 & 0,33 & 0,00 & 0,47 & 31,18 \\
\hline $\mathrm{PHVj}$ & 4,00 & 0,00 & 3,94 & 0,00 & 3,02 & 0,00 & 0,28 & 0,00 & 0,58 & 30,91 \\
\hline
\end{tabular}

${ }^{1}$ Dados transformados em $\sqrt{x+1}$ para análise estatística, mas na tabela são apresentados os valores originais. ${ }^{2}$ Dados transformados em arc sen $\sqrt{x / 100}$ para análise estatística, mas na tabela são apresentados os valores originais.

Efeito do sulfentrazone

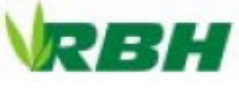

Comparando-se o controle com o
tratamento onde foi aplicado apenas 
sulfentrazone $(\mathrm{C} x$ apenas $\mathrm{H})$, verificou-se que não houve diferença estatística para número de tubérculos, umidade de solo (Tabela 4) e biomassa seca de raiz (Tabela 5). As outras variáveis mostraram valores maiores no controle que naqueles tratados com sulfentrazone ( $\mathrm{C}$ x apenas $\mathrm{H})$ (Tabelas 4 a 6$)$.

Tabela 4. Valores dos contrastes para número de tubérculos e de brotações, altura média de plantas e porcentagem de umidade do solo. Campinas, SP, 2003.

\begin{tabular}{lcccc}
\hline \multirow{2}{*}{ Contrastes } & \multicolumn{4}{c}{ Valor e significância do contraste } \\
\cline { 2 - 5 } & $\begin{array}{c}\text { Número de } \\
\text { tubérculo }^{1}\end{array}$ & $\begin{array}{c}\text { Número de } \\
\text { brotações }\end{array}$ & $\begin{array}{c}\text { Altura média } \\
\text { plantas }\end{array}$ & $\begin{array}{c}\text { \% Umidade do } \\
\text { solo }^{2}\end{array}$ \\
\hline C x H & $1,02^{3}$ & $2,20^{*}$ & $20,28^{*}$ & $-3,37$ \\
C x CH & $8,02^{*}$ & $14,74^{*}$ & $143,60^{*}$ & $-43,95^{*}$ \\
SH x CH & $6,41^{*}$ & $14,09^{*}$ & $120,58^{*}$ & $-10,24^{\text {s }}$ \\
C X P & 0,68 & 0,65 & $5,74^{*}$ & $-8,74^{*}$ \\
C x CP & $5,46^{*}$ & $7,46^{*}$ & $74,26^{*}$ & $-40,75^{*}$ \\
SP x CP & 2,09 & $-0,15^{\text {s }}$ & $-6,60$ & $-20,70^{*}$ \\
CX V & $-0,90$ & $-1,18^{*}$ & $-0,28$ & $-1,26$ \\
C x CV & 6,49 & $12,85^{*}$ & $127,46^{*}$ & $-46,52^{*}$ \\
SV x CV & 1,83 & $8,42^{*}$ & $72,16^{*}$ & $-17,97^{*}$ \\
HVa x HVd & 0,18 & 0,00 & 0,00 & $-0,55$ \\
HVa x HVj & 0,00 & 0,00 & 0,00 & 1,84 \\
HVd x HVj & $-0,18$ & 0,00 & 0,00 & 2,39 \\
HVax PHVa & 0,00 & 0,00 & 0,00 & $-3,42$ \\
HVdx PHVd & $-0,12$ & 0,00 & 0,00 & $-0,97$ \\
HVj x PHVj & 0,00 & 0,00 & 0,00 & $-3,19$ \\
PHVax HVd & 0,06 & 0,00 & 0,00 & 1,89 \\
PHVax HVj & 0,00 & 0,00 & 0,00 & 2,07 \\
PHVdx HVj & $-0,06$ & 0,00 & 0,00 & 0,17 \\
\hline${ }^{1}$ Dados transformados em & $\sqrt{x+1}$ para análise estatística. ${ }^{2}$ Dados transformados em arc. sen $\sqrt{x / 100}$ para análise \\
estatística. ${ }^{3} *$ : contraste & significativo a 5\%. & & &
\end{tabular}

Exceto para umidade do solo, em todas as outras variáveis analisadas, verificou-se que os tratamentos com o herbicida apresentaram valores inferiores ao do controle (Tabela 4 a 6) demonstrando que o produto controlou $\mathrm{o}$ desenvolvimento inicial da tiririca. De acordo com Velini \& Negrisoli (2000), uma camada de palha de 10 a $15 \mathrm{t} \mathrm{ha}^{-1}$, pode interceptar, aproximadamente, 99,4 e $99,5 \%$ da calda aplicada, respectivamente. No caso do sulfentrazone, provavelmente devido à sua solubilidade, ele foi arrastado da palha até o solo onde pode controlar a tiririca. O teor de umidade do solo foi maior nos tratamentos com sulfentrazone que no controle (Tabela 4). Nesses vasos havia menor número de brotações de tiririca e, conseqüentemente, menor absorção de água pelas plantas.

Quando comparou-se os tratamentos com e sem sulfentrazone ( $\mathrm{SH}$ x $\mathrm{CH}$ ), verificouse que os números de brotações e de tubérculos e as biomassas frescas e secas da raiz, parte aérea e de tubérculos foram maiores no tratamento sem sulfentrazone que naqueles com o produto, comprovando sua eficácia (Tabelas 4 a 6). As plantas de tiririca tratadas com sulfentrazone, após emergirem do solo, tornavam-se necróticas e morriam quando expostas à luz. Segundo Vencill (2002), plantas 
sensíveis a sulfentrazone, sofrem ruptura da protoporfirogênio-oxidase durante o processo membrana, que se inicia pela inibição da da síntese da clorofila.

Tabela 5. Valores dos contrastes para biomassas frescas de raiz, parte aérea e de tubérculos. Campinas, SP, 2003.

\begin{tabular}{lccc}
\hline \multirow{2}{*}{ Contrastes } & \multicolumn{3}{c}{ Valor do contraste } \\
\cline { 2 - 4 } & $\begin{array}{c}\text { Biomassa fresca } \\
\text { da raiz }\end{array}$ & $\begin{array}{c}\text { Biomassa fresca da parte } \\
\text { aérea }\end{array}$ & $\begin{array}{c}\text { Biomassa fresca do } \\
\text { tubérculo }\end{array}$ \\
\hline C x H & $8,71^{*}$ & $9,99^{*}$ & $4,28^{*}$ \\
C x CH & $57,53^{*}$ & $49,48^{*}$ & $34,49^{*}$ \\
SH x CH & $85,47^{*}$ & $61,92^{*}$ & $15,64^{*}$ \\
C x P & 3,43 & 6,78 & $4,86^{*}$ \\
C x CP & $28,53^{\text {s }}$ & 24,19 & $26,24^{*}$ \\
SP x CP & 13,50 & 5,12 & $8,58^{*}$ \\
C x V & $-23,16^{*}$ & $-20,89^{*}$ & 0,06 \\
C x CV & 34,07 & $46,94^{*}$ & $30,50^{*}$ \\
SV x CV & 15,09 & 54,32 & 3,67 \\
HVa x HVd & 1,83 & 0,00 & 0,40 \\
HVa x HVj & $-1,28$ & 0,00 & 0,22 \\
HVd x HVj & $-3,11$ & 0,00 & $-0,18$ \\
HVa x PHVa & $-4,18$ & 0,00 & 0,50 \\
HVd x PHVd & $-3,38$ & 0,00 & $-0,56$ \\
HVj x PHVj & 0,06 & 0,00 & $-0,68$ \\
PHVa x PHVd & 2,62 & 0,00 & $-0,66$ \\
PHVa x PHVj & 2,95 & 0,00 & $-0,96$ \\
PHVd x PHVj & 0,33 & 0,00 & $-0,30$ \\
\hline
\end{tabular}

*: contraste significativo a $5 \%$.

Quando comparou-se os tratamentos com e sem sulfentrazone ( $\mathrm{SH} \times \mathrm{CH}$ ), verificouse que os números de brotações e de tubérculos e as biomassas frescas e secas da raiz, parte aérea e de tubérculos foram maiores no tratamento sem sulfentrazone que naqueles com o produto, comprovando sua eficácia (Tabelas 4 a 6). As plantas de tiririca tratadas com sulfentrazone, após emergirem do solo, tornavam-se necróticas e morriam quando expostas à luz. Segundo Vencill (2002), plantas sensíveis a sulfentrazone, sofrem ruptura da membrana, que se inicia pela inibição da protoporfirogênio-oxidase durante o processo da síntese da clorofila.

\section{Efeito da deposição da palha sobre o solo}

O tratamento onde foi aplicado apenas palha $(\mathrm{C} \times \mathrm{P})$ apresentou a altura média das plantas e a biomassa fresca de tubérculos maiores que o controle (Tabela 4). A maior altura das plantas da tiririca foi devida ao seu estiolamento causado pela cobertura do solo fato este que, em condições de campo, torna as plantas mais suscetíveis a danos mecânicos (Rizzardi et al., 2006). Fleck et al. (2002) destacaram que, sob palha, ocorre atraso no desenvolvimento das plantas daninhas, mas este efeito não foi observado para a tiririca. A umidade do solo foi maior sob palha. Para as outras variáveis, não houve diferença entre o controle e a adição de palha ao solo (Tabelas de 4 a 6). 
Tabela 6. Valores dos contrastes para biomassas secas de raiz, parte aérea e de tubérculos. Campinas, SP, 2003.

\begin{tabular}{lccc}
\hline Contrastes & \multicolumn{3}{c}{ Valor do contraste } \\
\cline { 2 - 4 } & $\begin{array}{c}\text { Biomassa seca da } \\
\text { raiz }\end{array}$ & $\begin{array}{c}\text { Biomassa seca da parte } \\
\text { aérea }\end{array}$ & $\begin{array}{c}\text { Biomassa seca de } \\
\text { tubérculo }\end{array}$ \\
\hline C x H & 1,02 & $1,70^{*}$ & $0,64^{*}$ \\
C x CH & $6,71^{*}$ & $9,79^{*}$ & $5,06^{*}$ \\
SH x CH & $11,34^{*}$ & $9,55^{*}$ & $3,11^{*}$ \\
C x P & 0,43 & $1,02^{*}$ & 0,52 \\
C x CP & 3,66 & $5,30^{*}$ & $3,61^{*}$ \\
SP x CP & 2,93 & 0,69 & $1,20^{*}$ \\
C x V & $-3,32$ & $-2,17^{*}$ & $-0,22$ \\
C x CV & 2,68 & $9,27^{*}$ & $4,26^{*}$ \\
SV x CV & $-0,75$ & $7,98^{*}$ & 0,73 \\
HVa x HVd & $-0,06$ & 0,00 & 0,06 \\
HVa x HVj & 0,02 & 0,00 & 0,02 \\
HVd x HVj & 0,08 & 0,00 & $-0,04$ \\
HVa x PHVa & $-0,42$ & 0,00 & 0,07 \\
HVd x PHVd & $-0,09$ & 0,00 & $-0,10$ \\
HVj x PHVj & $-0,12$ & 0,00 & $-0,17$ \\
PHVa x PHVd & 0,28 & 0,00 & $-0,12$ \\
PHVa x PHVj & 0,33 & 0,00 & $-0,22$ \\
PHVd x PHVj & 0,05 & 0,00 & $-0,11$ \\
\hline
\end{tabular}

*: contraste significativo a $5 \%$.

De modo geral, quando comparados com o controle, todos os tratamentos onde foi adicionada palha ao solo, reduziram o desenvolvimento inicial da tiririca mostrando decréscimo no número de brotações e de tubérculos, na altura média de plantas e na biomassa fresca e seca de tubérculo e na biomassa fresca da parte aérea $(\mathrm{C} \times \mathrm{CP})$. A maior variabilidade nas plantas de tiririca foi observada na biomassa seca do sistema radicular, seguido pela biomassa seca da parte aérea e por fim, a biomassa seca dos tubérculos (Tabela 6).

A camada de palha mantida sobre o solo, além de protegê-lo da radiação solar, melhora a sua estrutura, aumenta a CTC, dissipa a energia do impacto das gotas de chuva, reduz a evaporação da água e modifica a temperatura além de constituir em reserva de nutrientes para as plantas e a biota do solo (Rosolem et al., 2003). Atua ainda como barreira física para plântulas em emergência, alterando o balanço hídrico e modificando a qualidade e a quantidade de luz que incide no solo interferindo também na amplitude térmica do solo (Kuva, 2006). Embora a germinação e o estabelecimento das plântulas sejam dependentes da espécie avaliada e variam em alguns casos, de semente para semente dentro de uma mesma espécie, o balanço dos fatores mencionados por Kuva (2006) é essencial para seu desenvolvimento. $\mathrm{O}$ desencadeamento da brotação da tiririca é altamente dependente de fatores externos como a intensidade e a qualidade da radiação luminosa, da temperatura do solo e a disponibilidade de água (Fernandez-Quintanilla, 1988) sendo que estes 
fatores são bastante alterados pelas culturas e pelo manejo do solo.

Segundo Nemoto et al. (1995), sob 30\% de sombreamento, ocorrem reduções no desenvolvimento da parte aérea e do sistema subterrâneo da tiririca. A presença de palha nas horas mais quentes do dia protege a superfície do solo e durante a noite reduz a dissipação do calor retido, favorecendo o desenvolvimento de espécies com reservas em seus dissemínulos que possam vencer a barreira física imposta pela palha (Egley \& Duke, 1995). Silva et al. (2003) observaram que não houve redução na emissão de brotação da tiririca com a adição ao solo de até $8 \mathrm{t} \mathrm{ha}^{-1}$ de palha de cana-de-açúcar; ocorreu apenas efeito retardatário. Com $16 \mathrm{tha}$ ${ }^{1}$ ocorreu redução no número de brotações, mas a biomassa fresca da parte aérea e o desenvolvimento de novos tubérculos não foram afetados.

A brotação da tiririca é regulada pela temperatura. Em solo descoberto, a radiação solar aumenta a flutuação diária da temperatura principalmente próxima à superfície do solo (Rubin \& Benjamin, 1984) sendo observado que a brotação dos tubérculos e a elongação das hastes ocorrem mais rapidamente (Nishimoto, 2001). Segundo esse autor, a flutuação térmica diária parece ser um mecanismo fisiológico para que ocorra quebra da dormência e elongação da haste da tiririca.

O teor de umidade do solo foi maior no tratamento com palha que no controle (Tabela 4) devido a menor incidência de luz e menores perdas de calor e de evaporação da água. Rozeff (1995) observou que ocorre retenção de umidade no palhiço o que é uma vantagem em locais com problema de déficit hídrico, pois diminui a necessidade de irrigação. As variações microclimáticas como o teor de água do solo é um dos fatores mais importantes que é alterado pela camada de palha deixada sobre o solo. Como o período de colheita da cana-deaçúcar é longo, em área sem cobertura, o desenvolvimento da cultura e das plantas daninhas fica sob a ação de condições de baixa umidade e temperatura, e no final da safra (de outubro a novembro) ocorrem umidades e temperaturas mais elevadas estando as plantas mais sensíveis a mudanças do tempo. No solo coberto, além de ocorrer menor variação térmica, a disponibilidade de água mesmo nos meses de junho a agosto por ser a maior (Kuva, 2006).

O número de brotações e a umidade do solo foram maiores no tratamento com palha. As biomassas fresca e seca dos tubérculos e a biomassa seca da raiz foram maiores no tratamento sem palha. (sem $\mathrm{P}$ x com $\mathrm{P}$ ). $\mathrm{Na}$ figura 1 é apresentada a comparação entre os diferentes tratamentos com palha. Foi observado que a aplicação de sulfentrazone antes, depois e mesmo junto com a vinhaça sobre a palha aumenta o teor de umidade desta quando comparada ao tratamento com apenas esse resíduo vegetal.

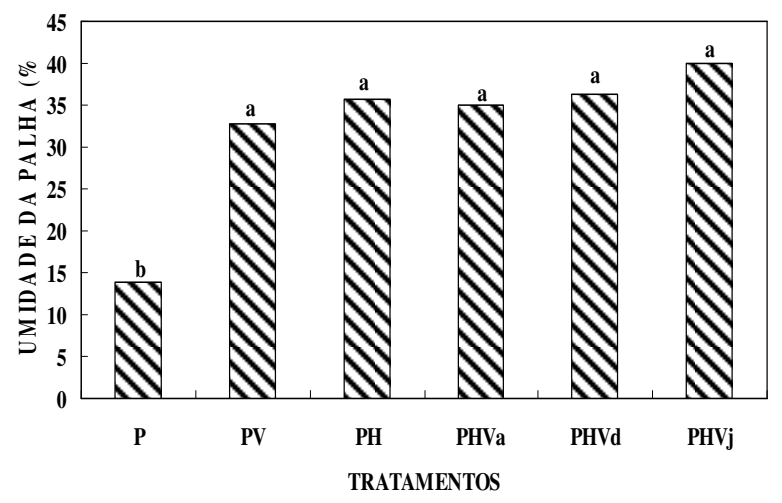

Figura 1. Efeito dos tratamentos com apenas palha $(\mathrm{P})$, palha + vinhaça $(\mathrm{PV})$, palha + sulfentrazone $(\mathrm{PH})$, palha + herbicida + vinhaça aplicada antes do herbicida (PHVa); palha + herbicida + vinhaça aplicada depois do herbicida (PHVd); e palha + herbicida + vinhaça aplicada junto com o herbicida ( $\mathrm{PHVj})$ no teor de umidade da palha. Barras precedidas por letras iguais não diferem entre si pelo teste de Duncan a 5\%. Campinas, SP, 2003. 


\section{Efeito da aplicação da vinhaça}

A vinhaça contém mais de $93 \%$ de água (Glória, 1976) e esta atua de maneira decisiva nas reações enzimáticas, na solubilização e no transporte de metabólitos e como reagente na digestão hidrolítica de proteínas, carboidratos e lipídeos de tecido de reserva (Castro \& Vieira, 2001). Quando foi observado o efeito da aplicação de apenas vinhaça no solo descoberto (Tabela 3) em relação ao controle, verificou-se que este resíduo aumentou o crescimento de todas as estruturas da tiririca, mas houve diferença significativa apenas para o número de brotações, as biomassas frescas e secas da raiz e da parte aérea da tiririca $(\mathrm{C} \times \mathrm{V})$. A tiririca mostrou ser bastante tolerante a altas concentrações de potássio, pois seu nível no solo antes da aplicação da vinhaça $\left(3,6 \mathrm{mmol}_{\mathrm{c}}\right.$ $\mathrm{dm}^{-3}$ ) é considerado elevado por Raij et al. (1996).

Quando foi avaliado o efeito dos contrastes comparando todos os tratamentos onde foi aplicado vinhaça com o controle, observou-se que houve redução do desenvolvimento inicial da tiririca com diminuição do número e da altura média das brotações (Tabela 4) e das biomassas frescas e secas da parte aérea e dos tubérculos (Tabelas 5 e 6). Esse efeito está mais associado à aplicação de vinhaça em tratamentos onde foi adicionada palha e aplicado sulfentrazone. O nível de umidade do solo foi maior nos tratamentos com vinhaça que no controle.

$\mathrm{O}$ número de brotações, a altura e a biomassa seca da parte aérea foram maiores no tratamento sem vinhaça que naqueles onde foi aplicado este resíduo (SV x CV). O teor de umidade do solo foi maior nos tratamentos onde foi aplicada vinhaça que naqueles sem o resíduo (Tabelas de 4 a 6).

Efeito da interação entre aplicação de sulfentrazone, adição de palha ao solo e o meios de aplicação da vinhaça
Nos tratamento sem palha, não houve diferença entre aplicar a vinhaça antes, depois ou mesmo em mistura com o sulfentrazone para todas as variáveis analisadas (Tabelas 4 a 6). Nesses tratamentos, o sulfentrazone controlou o desenvolvimento inicial da tiririca, eliminando todas as brotações. Buss et al. (1978) avaliaram o efeito de ametryne em mistura com vinhaça. Sugeriram que a vinhaça adsorveria o herbicida e que este seria liberado gradativamente. Prata et al. (2001) observaram que, de modo geral, a vinhaça afeta o comportamento dos herbicidas atuando tanto na sorção como na degradação.

Quando comparou-se os tratamentos com sulfentrazone aplicado antes, depois e em mistura com vinhaça sem e com a adição de palha, foi observado que não houve diferença em nenhuma das variáveis estudados (Tabelas de 4 a 6).

\section{Efeito da interação entre aplicação de sulfentrazone, adição de palha ao solo e o meios de aplicação da vinhaça}

Kuva (2006) relatou que a presença de uma camada de palha sobre o solo promove alteração na dinâmica dos principais herbicidas aplicados à cultura de cana-de-açúcar. $\mathrm{Na}$ colheita convencional da cana-de-açúcar, os herbicidas de aplicação em pré-emergência são aplicados diretamente ao solo, mas sobre a palha, estes produtos necessitam vencer esta barreira. Para sulfentrazone não foi observado sua retenção sob palha, pois verificou-se que houve controle do desenvolvimento inicial de plantas de tiririca tanto quanto a vinhaça foi aplicada antes, depois ou em mistura com o produto (Tabela 4 a 6 ).

Embora a vinhaça seja fonte de água e nutrientes e mesmo quando associada à palha, a aplicação de sulfentrazone afetou o desenvolvimento da tiririca. Acredita-se que a presença da palha associada à aplicação da vinhaça causou mudanças na temperatura do 
solo e juntamente com o sombreamento prejudicaram a tiririca. Segundo Magalhães (1967), o sombreamento do solo influencia o desenvolvimento dos rizomas da tiririca inibindo a produção de tubérculos sem eliminálos. Nessa condição, o tubérculo não se desenvolve e podem sofrer a ação de alguns microrganismos (Blanco, 2006). A temperatura influencia ainda na absorção de água, nos processos bioquímicos e na velocidade e na uniformidade da germinação (Kuva, 2006).

\section{Conclusões}

Concluiu-se que sulfentrazone, tanto em aplicação isolada como sobre palha, ou associado a vinhaça aplicada antes depois ou em mistura com o produto, controlou $\mathrm{O}$ desenvolvimento inicial da tiririca.

A deposição da palha sobre o solo reduziu o desenvolvimento inicial da tiririca, porém aumentou a altura das plantas devido ao estiolamento destas.

A vinhaça aplicada sobre o solo descoberto e sem herbicida estimulou o desenvolvimento da tiririca; entretanto, associada a palha e ao sulfentrazone, reduziu o seu crescimento. Não houve diferença entre aplicação de vinhaça antes, depois e mesmo em mistura com sulfentrazone nos tratamentos sem ou com palha.

\section{Referências}

AZANIA, C.A.M.; AZANIA, A.A.P.M.; PAVANI, M.C.M.D.; ALVES, P.L.C.A. Desenvolvimento da tiririca (Cyperus rotundus) influenciado pela presença e ausência de palha de cana-de-açúcar e herbicidas. Planta Daninha, v.24, n.1, p.2935, 2006.

BLANCO, F.M.G. Tubérculo invasor. Cultivar, n.6, p.3-7, 2006.
BUSS, A. Viabilidade do uso de herbicidas em mistura com vinhaça em soqueiras de cana-deaçúcar. 1977. 68p Dissertação (Mestrado em Solos e Nutrição de Plantas) Universidade de São Paulo, Piracicaba, 1977.

BUSS, A.; SILVA, S.A. Aplicação dos herbicidas oryzalin e tebuthiuron em mistura com vinhaça em cana soca. In: SEMINÁRIO BRASILEIRO DE HERBICIDAS E ERVAS DANINHAS, 11., Londrina, 1976. Anais.... Londrina: Sociedade Brasileira de Herbicidas e Ervas Daninhas. p.65-66.

CASTRO, P.R.C. ; VIEIRA, E.L. Aplicações de reguladores vegetais na agricultura tropical. Guaíba: Agropecuária, 2001. 132p.

CHRISTOFFOLETI, P.J.; BACCHI, O.O.S. Efeito da aplicação de vinhaça sobre a população e controle químico das plantas daninhas na cultura da cana-de-açúcar (Saccharum spp). Planta Daninha, v.8, n.2, p.60-70, 1985.

EGLEY, G.H. ; DUKE, S. Physiology of weed seed dormancy and germination. In: DUKE, S.O. Weed physiology. I. Reproduction and ecophysiology. Florida: CRC Press, 1995. p.27-64.

FERNANDES-QUINTANILLA, C. Studying the population dynamics of weeds. Weed Research, v.28, n.3, p.443-447, 1988.

FERRI, M.V.W. ; VIDAL, R.A. Controle de plantas daninhas na cultura da soja através do herbicida acetochlor em sistema de semeadura direta e preparo convencional. Planta Daninha, v.20, n.2, p. 283-290, 2002.

FLECK, N.G.; RIZZARDI, M.A.; VIDAL, R.A.; MEROTTO JR, A.; AGOSTINETTO, D.; BALBINOT JR, A.A. Período crítico para o controle de Brachiaria plantaginea em função de épocas de semeadura da soja após a dessecação da cobertura vegetal. Planta Daninha, v.20, n.2, p.53-62, 2002. 
GLÓRIA, N.A. Emprego da vinhaça para fertilização. Piracicaba: CODISTIL, 1976. s.n.p..

KUVA, M.A. Banco de sementes, fluxo de emergência e fitossociologia de comunidade de plantas daninhas em agroecossistema de canacrua. Tese (doutorado) - Universidade Estadual Paulista, Faculdade de Ciências Agrárias e Veterinárias, Jaboticabal. 2006. 105p.

MAGALHÃES, A. C. Observações sobre o efeito da luz no crescimento da tiririca, Cyperus rotundus L.. Bragantia, v.26, n.1, p.131-142, 1967

MARTINS, D.; VELINI, E.D.; MARTINS, C.; SOUZA, L.S. Emergência em campo de dicotiledôneas infestantes em solo coberto com palha de cana-de-açúcar. Planta Daninha, v.17, n.1, p.151-161, 1999.

MEDEIROS, D. Efeitos da palha de cana-deaçúcar (Saccharum spp.) sobre o manejo de plantas daninhas e dinâmica do banco de sementes. Piracicaba, 2001. p.10-21. Dissertação (Mestrado) - Escola Superior de Agricultura "Luiz de Queiróz", Universidade de São Paulo.

NEMOTO, M.C.M.; ALVES, P.L.C.A.; PITELLI, R.A.; NEMOTO, L.R.P. Comportamento da tiririca (Cyperus rotundus L.) sob diferentes níveis de adubação fosfatada e de sombreamento. Planta Daninha, v.13, n.3, p.50-55, 1995.

NISHIMOTO, R.K. Purple nutsedge tuber sprouting. Weed Biology and Management, v.1, n.2, p.203-208, 2001.

PIMENTEL GOMES, F. Curso de estatística experimental. Piracicaba: Livraria Nobel. 1976. p.44-46.

PRATA, F.; LAVORENTI, A.; REGITANO, J.B.; TORNASIELO, V.L. Degradação e sorção de ametrina em dois solos com aplicação de vinhaça. Pesquisa Agropecuária

Brasileira, v.36, p.975-981, 2001.

QUINTELA, A.C.R.; ANDRADE, L.A.B.; CORRÊA, J.B.D.; RESENDE, P.M.; VIEIRA, G.G. Controle de plantas daninhas em cana crua (cultivar RB835089) no sistema integrado palhiço, herbicida e vinhaça. STAB, v.20, n.2, p.38-42, 2002.

RAIJ, B. van; CANTARELLA, H; QUAGGIO, J.A.; FURLANI, A.M.C. (Eds.) Recomendações de adubação e calagem para o Estado de São Paulo. $2^{a}$. ed. Campinas: Instituto Agronômico \& Fundação IAC, 1996. 285p. (Boletim técnico, 100)

RIZZARDI, M.A.; SILVA, S.F.; VARGAS, L. Controle de plantas daninhas em milho em função da quantidade de palha de nabo forrageiro. Planta Daninha, v.24, n.1, p.263270, 2006.

RODELLA, A.A.; FERRARI, S.R. A composição da vinhaça e efeitos de sua aplicação como fertilizante na cana-de-açúcar. Brasil Açucareiro, v.90, n.2, p.380-387, 1997.

ROSOLEM, C.A.; CALONEGO, J.C.; FOLONI, J.S.S. Lixiviação de potássio da palha de espécies de cobertura de solo de acordo com a quantidade de chuva aplicada. Revista Brasileira de Ciência do Solo, v.27, n.2, p.355-362, 2003.

ROZEFF, N. Harvest comparisons of green and burned sugarcane in Texas. International Sugar Journal, v. 97, n.1, p.501-506, 1995.

RUBIN, B. ; BENJAMIN, A. Solar heating of the soil: involvement of environmental factors in the weed control process. Weed Science, v.32, n.3, p.138-142, 1984.

SILVA, J.R.V.; COSTA, N.V.; MARTINS, D. Efeito da palhada de cultivares de cana-deaçúcar na emergência de Cyperus rotundus. Planta Daninha, v.21,n.3, p.373-380, 2003. 
TEASDALE, J.R. Contribution of cover crops to weed management in sustainable agricultural systems. Journal of Production Agriculture, v.9, n.2, p.475-479, 1996.

TRIVELLIN, P.C.O.; RODRIGUES, J.C.S; VICTORIA, R.L.; REICHARDT, K. Utilização da soqueira de cana-de-açúcar de início de safra, do nitrogênio da aquamônia ${ }^{15} \mathrm{~N}$ e uréia ${ }^{15} \mathrm{~N}$ aplicação ao solo em complemento a vinhaça. Pesquisa Agropecuária Brasileira, v. 31, n.3, p.89-99, 1996.

VELINI, E.D. ; NEGRISOLI, E. Controle de plantas daninhas em canacrua. In: CONGRESSO BRASILEIRO DA CIÊNCIA DAS PLANTAS DANINHAS, 22., Fóz do Iguaçú, 2000. Anais... Londrina: SBCPD, 2000. p. 148-164.

VOLL, C.E. Aplicação de vinhaça e do extrato de palhiço de cana-de-açúcar no controle de plantas daninhas. 2005. 45p. Dissertação (Mestrado em Fitotecnia). Universidade de São Paulo, Piracicaba, 2005.

VENCILL, W.D. Herbicide Handbook. 2002. $8^{\mathrm{a}}$.ed. Lawrence: Weed Science Society of America. 2002. p.405-406.

ZANDSTRA, B.H.; NISHIMOTO, R.K. Movement and activity of glyphosate in purple nutsedge. Weed Science, v.25, n.3, p.268-274, 1977. 